\title{
Direct and indirect pathways for the spread of African swine fever and other porcine infectious diseases: An application of the mental models approac
}

\author{
Francesco Galli ${ }^{1}$, Brian Friker ${ }^{1}$, Angela Bearth $^{2}$, and Salome Duerr ${ }^{1}$ \\ ${ }^{1}$ Universitat Bern Veterinary Public Health Institute \\ ${ }^{2}$ Eidgenossische Technische Hochschule Zurich Institut fur Umweltentscheidungen
}

June 21, 2022

\begin{abstract}
In this study, we investigated the occurrence of direct and indirect infectious disease transmission pathways among pig farms in Switzerland, as well as their specific relevance for the spread of African swine fever, porcine reproductive and respiratory syndrome (PRRS), and enzootic pneumonia. Data were collected using an adapted mental models approach, involving initial interviews with experts in the field of pig health and logistics, semi-structured interviews with pig farmers, and a final expert workshop, during which all identified pathways were graded by their predicted frequency of occurrence, their likelihood of spread of the three diseases of interest, and their overall relevance considering both parameters. As many as 24 disease pathways were identified in four areas: pig trade, farmer encounters, external collaborators, and environmental or other pathways. Two thirds of the pathways were expected to occur with moderate-to-high frequency. While both direct and indirect pig trade transmission routes were highly relevant for the spread of the three pathogens, pathways from the remaining areas were especially important for PRRS due to higher spread potential via aerosols and fomites. In addition, we identified factors modifying the relevance of disease pathways, such as farm production type and affiliation with trader companies. During the interviews, we found varying levels of risk perception among farmers concerning some of the pathways, which affected adherence to biosecurity measures and were often linked to the degree of trust that farmers had towards their colleagues and external collaborators. Our findings highlight the importance of integrating indirect disease pathways into existing surveillance and control strategies and in disease modelling efforts. We also propose that biosecurity training aimed at professionals and risk communication campaigns targeting farmers should be considered to mitigate the risk of disease spread through the identified pathways.
\end{abstract}




\title{
Direct and indirect pathways for the spread of African swine fever and other porcine infectious diseases: An application of the mental models approach
}

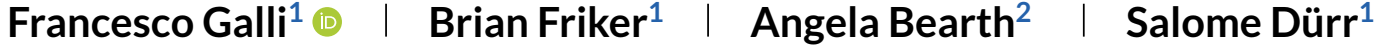

${ }^{1}$ Veterinary Public Health Institute (VPHI), Vetsuisse Faculty, University of Bern, Bern, Switzerland

${ }^{2}$ Consumer Behavior, Institute for Environmental Decisions, Swiss Federal Institute of Technology Zurich (ETHZ), Zurich, Switzerland

\section{Correspondence}

Francesco Galli, Veterinary Public Health Institute (VPHI), Vetsuisse Faculty, University of Bern, Schwarzenburgstrasse 161, Bern, 3097 Switzerland.

Email: francesco.galli@vetsuisse.unibe.ch

\section{Funding information}

Swiss National Science Foundation,

Grant/Award Number: 182404

\begin{abstract}
In this study, we investigated the occurrence of direct and indirect infectious disease transmission pathways among pig farms in Switzerland, as well as their specific relevance for the spread of African swine fever, porcine reproductive and respiratory syndrome (PRRS), and enzootic pneumonia. Data were collected using an adapted mental models approach, involving initial interviews with experts in the field of pig health and logistics, semi-structured interviews with pig farmers, and a final expert workshop, during which all identified pathways were graded by their predicted frequency of occurrence, their likelihood of spread of the three diseases of interest, and their overall relevance considering both parameters. As many as 24 disease pathways were identified in four areas: pig trade, farmer encounters, external collaborators, and environmental or other pathways. Two thirds of the pathways were expected to occur with moderate-to-high frequency. While both direct and indirect pig trade transmission routes were highly relevant for the spread of the three pathogens, pathways from the remaining areas were especially important for PRRS due to higher spread potential via aerosols and fomites. In addition, we identified factors modifying the relevance of disease pathways, such as farm production type and affiliation with trader companies. During the interviews, we found varying levels of risk perception among farmers concerning some of the pathways, which affected adherence to biosecurity measures and were often linked to the degree of trust that farmers had towards their colleagues and external collaborators. Our findings highlight the importance of integrating indirect disease pathways into existing surveillance and control strategies and in disease modelling efforts. We also propose that biosecurity training aimed at professionals and risk communication campaigns targeting farmers should be considered to mitigate the risk of disease spread through the identified pathways.
\end{abstract}

KEYWORDS

African swine fever, enzootic pneumonia, livestock, mental models, porcine reproductive and respiratory syndrome, spread 


\section{1 | INTRODUCTION}

Despite constant research advances, porcine infectious diseases continue to pose a threat to the international pig production industry (STAR-IDAZ IRC, 2021). Owing to the absence of trade with countries inside and outside the European Union, Switzerland has achieved a high level of health in domestic pigs (Swiss Federal Food Safety and Veterinary Office, 2021). Nonetheless, the porcine reproductive and respiratory syndrome (PRRS) virus is occasionally reintroduced in the country (Nathues et al., 2016; République et canton de Neuchâtel, n.d.), and enzootic pneumonia (EP) outbreaks recurred despite the national rollout of a control program in the early 2000s (M. B. Linhares et al., 2015; Stärk et al., 2007). To date, African swine fever (ASF) has not been detected in Switzerland but is present in Germany (Sauter-Louis et al., 2021), and a recent Swiss study identified potential introduction routes into Switzerland (Vargas Amado et al., n.d.).

Livestock trade is considered one of the main mechanisms of infectious disease spread among production animals. In countries with industrialized livestock systems, animal movements are often systematically recorded. With the availability of these data, trade network analysis has been a productive research branch in the last decade (Lentz et al., 2016; Salines et al., 2017; J. Schulz, Boklund, et al., 2017). However, the spread of disease cannot always be linked to trade. During a classical swine fever (CSF) epidemic in the Netherlands, it was estimated that the number of new infections attributable to pig trade dropped from $69 \%$ before detection to $13 \%$ after detection, at which point indirect infection routes became dominant (Elbers et al., 1999). Nonetheless, past studies have extensively focused on the characterization of trade-related pathways (Bajardi et al., 2012; Porphyre et al., 2020; Salines et al., 2017; Sterchi et al., 2019).

The available literature on indirect pathways describes visits of professionals (Brennan et al., 2008; Mcreynolds et al., 2014; Nöremark et al., 2013; Olofsson et al., 2014; Relun et al., 2015; Ribbens et al., 2009), equipment sharing (Brennan et al., 2008; Relun et al., 2015), encounters between farmers (Brennan et al., 2008; Mcreynolds et al., 2014; Nöremark et al., 2013; Relun et al., 2015; Ribbens et al., 2009) and animal carcass management (Brennan et al., 2008; Nöremark et al., 2013; Relun et al., 2015) as potential between-farm disease spread mechanisms, especially when coupled with low on-farm biosecurity (Brennan et al., 2008). The application of these findings to other contexts is often limited by heterogeneity across studies in terms of investigated pathways, type of livestock production, and focus on pathway characterization rather than on frequency of pathway occurrence. Moreover, in these studies, the relevance of each indirect contact type for the transmission of specific pathogens was not evaluated. The suboptimal synergy between the study of indirect disease pathways and infectious disease modelling is noticeable in recently published modelling studies in which indirect pathways are either not considered (Thakur et al., 2015) or included as simplified parameters that may not be able to capture the complexity behind certain contact structures (Galvis et al., 2021; Halasa et al., 2016).

When investigating indirect disease pathways, considering the knowledge and experiences of farmers is crucial. Using quantitative approaches to do so presents two substantial challenges: the potential of recall bias of farmers concerning their activities and of social desirability bias due to some farming practices that are linked with indirect disease pathways being frowned upon. Previous studies in the field of veterinary science and food security showed that the risk of incurring such biases can be mitigated by employing qualitative methodology (Bard et al., 2019; Bearth et al., 2014; Kuster et al., 2015; Mauroy et al., 2021; Suit-B et al., 2020; Vergne et al., 2016). A fruitful qualitative approach is the mental models approach (MMA), which is based on the notion that individuals build mental models to make sense of the world and make decisions based on their previous experiences and views of a particular issue (Jones et al., 2011). These mental models can ideally be explored in qualitative research (e.g., semi-structured interviews), as was suggested by Morgan et al. (2002) for the risk context. Their approach enables the elicitation of both laypeople and experts to identify risky practices and, at the same time, understand and compare mental models in the context of the population of interest.

The aim of our study was to identify, characterize, and classify both direct and indirect disease pathways between pig holdings. In addition, we directly related the acquired knowledge on pathways with their importance for the transmission of three highly relevant pig infectious diseases in the Swiss and international contexts: ASF, PRRS, and EP. To achieve this, we involved Swiss pig farmers and experts by using an adapted version of the MMA.

\section{2 | MATERIALS AND METHODS}

We used a qualitative design, namely an adapted version of the MMA. The original MMA is a methodological framework deploying both qualitative and quantitative tools (Morgan et al., 2002). In summary, MMA studies begin with a review of the available literature on the topic of interest, followed by expert elicitation to compensate for missing knowledge and to frame the problem within a specific context. By relying on the gained knowledge, interview guidelines are then developed to perform semi-structured interviews with laypeople, with the purpose of identifying their knowledge, attitudes, and perceptions that are subsequently quantified by means of a confirmatory quantitative questionnaire. Finally, an appropriate risk communication strategy is designed together with the experts, implemented, and evaluated in the field.

The aim of our study was not to create a risk communication strategy but rather to cover the scientific knowledge gap on indirect disease pathways among pig holdings. Therefore, we modified the original MMA as described previously by excluding the last three steps so that two first steps remained: semi-structured interviews with experts and semi-structured interviews with farmers. The findings were then deepened and confirmed within a final expert workshop to classify contact pathways by relevance for infectious disease spread.

A detailed description of the methodology used in both expert and farmer interviews is reported in Table S1, following the Consolidated Criteria for Reporting Qualitative Research (COREQ) checklist (Tong et al., 2007). 


\subsection{Expert interviews}

The initial enrolment of experts was made via the pig health board of the platform 'Livestock Health Switzerland' (https://www. nutztiergesundheit-schweiz.ch/), through which Swiss experts in the field of pig health and farming regularly meet to exchange on programmes and projects related to Swiss pig production and health. After interviewing these experts, we asked them to mention the names of other experts with relevant knowledge that we may interview. These recruitment efforts resulted in a final sample of six interviewed experts with a variety of backgrounds and fields of expertise: a livestock veterinarian from the German-speaking region, a livestock veterinarian from the French-speaking region, a veterinarian in the academic environment and specialized in pig health, two scientific collaborators from the Federal Food Safety and Veterinary Office, and a manager in the logistics department of a livestock trading company. In-person, semistructured interviews were conducted between August and December 2019. The six expert interviews lasted between 1 and $3 \mathrm{~h}$. The interviews were based on a list of potential disease transmission pathways in Switzerland that we previously compiled using the available literature. Experts were asked to review the list to include all possible contact pathways between Swiss pig farms that may lead to the spread of infectious diseases, as well as protective and risk factors that may modify the frequency of occurrence of such contacts and the likelihood of disease transmission. The list was updated after each interview to integrate newly gained knowledge from each expert. After the last interview, the gained information was summarized in a diagram consisting of disease pathways grouped by thematic areas and potential modifying factors.

\subsection{Farmer interviews}

A farmer interview guideline (Supporting Information 2) was generated based on the expert diagram. Mental models interviews consisted of first asking broad questions about a farmer's daily routines and work on the farm. Such questions usually did not yield relevant knowledge. Rather, they aimed at creating a pleasant atmosphere and building trust between the interviewer and interviewee to minimize the risk of social desirability bias. Subsequently, increasingly specific questions were asked. These allowed us to explore with the farmers all areas of the expert diagram and to limit recall bias.

A total of 21 farmers were sequentially selected via theoretical sampling (Corbin \& Strauss, 2012). Care was taken to include farmers with a variety of characteristics of interest, namely language region, production type, outdoor access for pigs, and the presence of other animal species on the premises. For 17 farmers, recruitment was performed by phone calls by SUISAG AG, a Swiss private pig health and breeding services company, with which approximately $80 \%$ of breeding farms and $50 \%$ of fattening farms of Switzerland are affiliated. Recruitment of the four farmers not affiliated with SUISAG AG was directly performed by the interviewers to ensure the representation of farmers out of the main production sector.
The interviews were carried out by three interviewers in one of three national languages (French, German, and Italian) according to the farmers' preferences, and the interviews took place between January and December 2020 (Table 1). The average interview duration was 48 min (shortest 27 min, longest $104 \mathrm{~min}$ ). Owners of different farm types were interviewed for a fair representation of the whole production chain: one nucleus herd holding, two breeding and weaning holdings, two weaning-only holdings, four Arbeitsteilige Ferkelproduktion (AFP) ring holdings, four fattening-only holdings, a gilt raising-to-weaning holding, a breading-to-fattening holding, and six closed production cycle holdings, where all stages from gilt raising to fattening were performed. The original plan was to meet all farmers on their farms; however, fieldwork was interrupted twice due to COVID-19-related restrictions in Switzerland. Therefore, 13 interviews were conducted on-farm, while the remaining eight were conducted either via Zoom or phone call.

A request for ethics approval to conduct farmer interviews based on the guidelines was submitted to the Ethics Committee of the Swiss Federal Institute of Technology Zurich. Ethics approval (EK 2019-N167) was obtained in December 2019. Farmers were asked to sign an informed consent form, and the recording of the interviews started after the farmer's permission was granted.

All interviews were transcribed thereafter. All segments of interest were coded in MaxQDA 2020 (VERBI Software, 2019). Each code corresponded to a single item-either a disease pathway or a modifying factor-from the expert diagram.

\subsection{Expert workshop}

After finalizing the analysis of farmers' interviews, we circled back to the experts by organizing a half-day Zoom workshop in February 2021. From the initial sample, five experts agreed to participate.

The workshop consisted of an initial presentation of the findings on each contact pathway from farmer interviews. Subsequently, a polling session was opened. By considering the presented findings, experts were asked to express their opinion on (a) frequency of occurrence and (b) likelihood of spread of ASF, PRRS, and EP for all identified pathways. Experts voted using a low/moderate/high scale for both questions separately. The definition of the response options 'low', 'moderate', and 'high' was meant to reflect the relevance of each pathway's frequency for potential disease transmission. This was discussed at the beginning of the workshop to ensure homogeneity in experts' understanding of the response options and thus in their responses. Any questions that arose were discussed in the workshop prior to voting. Each expert voted independently. Subsequently, poll results were shown, and a discussion took place. During the discussion, in case of non-unanimous answers in the polling round, experts were asked to come to a final agreement on the frequency of occurrence and likelihood of disease spread. In addition, they were encouraged to openly discuss factors potentially modifying the relevance of a pathway.

At the end of the workshop, the results were presented to the experts for review by means of risk assessment matrices 
TAB LE 1 Characteristics of farmer interviews and pig holdings of the farmers interviewed

\begin{tabular}{|c|c|c|c|c|c|}
\hline Interview & $\begin{array}{l}\text { Duration } \\
\text { (minutes) }\end{array}$ & Language & Farm production type & $\begin{array}{l}\text { Pigs have } \\
\text { outdoor access }\end{array}$ & $\begin{array}{l}\text { Other livestock } \\
\text { on premises }\end{array}$ \\
\hline 1 & 49 & German & Fattening & & \\
\hline 3 & 42 & German & Fattening & $x$ & $x$ \\
\hline 4 & 56 & German & Closed production cycle ${ }^{b}$ & $x$ & $x$ \\
\hline 7 & 29 & German & Weaning & & $\mathrm{x}$ \\
\hline 8 & 34 & German & Weaning & & $\mathrm{x}$ \\
\hline 9 & 53 & German & AFP ring farm ${ }^{a}$ & & $x$ \\
\hline 10 & 32 & German & Breeding, weaning & $x$ & $x$ \\
\hline 13 & 57 & French & Closed production cycle ${ }^{b}$ & $x$ & $\mathrm{x}$ \\
\hline 14 & 29 & German & Breeding, weaning, fattening & $x$ & $\mathrm{x}$ \\
\hline 15 & 104 & German & AFP ring farm ${ }^{a}$ & $x$ & $x$ \\
\hline 16 & 51 & French & AFP ring farm ${ }^{b}$ & & $x$ \\
\hline 17 & 55 & French & Fattening & $\mathrm{x}$ & $\mathrm{x}$ \\
\hline 18 & 59 & Italian & Breeding, weaning & $x$ & $x$ \\
\hline 19 & 37 & Italian & Closed production cycle ${ }^{b}$ & $\mathrm{x}$ & $x$ \\
\hline 20 & 76 & Italian & Gilt raising, breeding, weaning & $\mathrm{x}$ & \\
\hline 21 & 50 & German & Nucleus herd & & $x$ \\
\hline
\end{tabular}

Abbreviation: AFP, Arbeitsteilige Ferkelproduktion.

${ }^{a}$ Shared piglet production rings typical of the Swiss pig production chain.

${ }^{\mathrm{b}}$ Close production cycle farms are those performing all steps of pig production: gilt raising, breeding, weaning, and fattening.

(Manuele, 2013) in which value 1 was assigned to 'low', value 2 to 'moderate', and value 3 to 'high' votes for both questions, frequency of occurrence and likelihood for disease spread, per pathway and investigated disease (Figure 1). The two values were multiplied to obtain a disease-specific relevance scale for all pathways, ranging from 1, or 'very low relevance', to 9, or 'very high relevance'.

To mitigate potential peer pressure, after the workshop, we contacted the experts via email, providing them again with the results of the workshop and a final opportunity to suggest any changes. This did not result in any modification of the workshop results.

\section{3 | RESULTS}

\subsection{Expert interviews}

All experts mentioned disease spread pathways belonging to four distinct areas (Figure 2): (i) live pig transport-related contacts, such as direct trade or contamination via lorries and lorry drivers; (ii) farmer encounters, such as interactions at the carcass collection point or at the farm for sharing farming equipment; (iii) visits from exter- nal collaborators, such as veterinarians and feed advisors; and (iv) environment-related or other contacts, such as wild boar or other wild animal populations. Disease pathways initially mentioned by the experts are presented in the expert diagram (Figure 2) and are later described in the remaining results sub-sections.

Figure 2 also shows the four main aspects that were identified as protective or risk factors, potentially modifying the relevance of a certain type of contact for the spread of infectious diseases. First, both farmers' and external collaborators' awareness of on-farm biosecurity rules was considered crucial in defining the level of protection of a given farm against indirect contact pathways. For instance, veterinarians visiting several farms in the same day may represent a danger for disease introduction. However, this risk may become negligible if both farmers and veterinarians strictly follow biosecurity guidelines.

Second, affiliation of a farm with a trading company was deemed both a protective and a risk factor: traders offer professional and standardized services, and in theory (see the first two quotes in Table 2), they must abide by higher biosecurity standards. Nonetheless, compared to an average farmer, they visit a substantially larger number of holdings every day and hence have the potential to spread disease on a large scale. Pigs from many different batches come into contact 
TAB LE 2 Exemplary quotes from farmer interviews. A quote is given for each potential disease pathway that was identified or discussed with farmers during interviews. Sentences were translated to English from the original languages of the interviews

\begin{tabular}{|c|c|c|}
\hline Potential disease pathway & Interview & Exemplary quotes \\
\hline \multicolumn{3}{|r|}{ Pig trade } \\
\hline $\begin{array}{l}\text { Lorry contamination: Traces } \\
\text { from other pigs }\end{array}$ & 13 & $\begin{array}{l}\text { And those who come with a dirty lorry-I had that once or twice-and do not want to change their } \\
\text { practices, well, I tell them 'there are others' [other trading companies]. Yes, at some point it [the } \\
\text { lack of compliance to hygiene rules] has to stop. }\end{array}$ \\
\hline $\begin{array}{l}\text { Contamination via lorry } \\
\text { driver }\end{array}$ & 4 & $\begin{array}{l}\text { The driver cannot come in during animal loading, he is just on the ramp. There has also been one who } \\
\text { thought he wanted to do it well, so I had to say 'Out, that is not possible'. He wanted to be helpful, } \\
\text { but that is just it. I had to be a bad guy [and ask him to get out]. }\end{array}$ \\
\hline $\begin{array}{l}\text { Sharing of boars between } \\
\text { farmers }\end{array}$ & 5 & $\begin{array}{l}\text { That is certainly a danger when I take the sow to the boar, which is why I am considering having a } \\
\text { boar myself. }\end{array}$ \\
\hline Transport done by farmer & 1 & $\begin{array}{l}\text { In the past, I have transported pigs to the village butcher myself because they had something and } \\
\text { could not be taken to a large butcher's shop. }\end{array}$ \\
\hline \multicolumn{3}{|r|}{ Farmer encounters } \\
\hline $\begin{array}{l}\text { Farmer encounters outside } \\
\text { the premises }\end{array}$ & 1 & $\begin{array}{l}\text { I do not meet any colleague in my work clothes. In the afternoon I indeed meet some colleagues, or in } \\
\text { committees and commissions to which I belong and where I meet work colleagues, but never in } \\
\text { work clothes. }\end{array}$ \\
\hline $\begin{array}{l}\text { Sharing of pig farming } \\
\text { equipment }\end{array}$ & 10 & $\begin{array}{l}\text { The [anaesthesia] equipment [for piglet castration] is at my place, in the boiler room. At the } \\
\text { beginning, there were five of us using it, now there are three. The tool is in my place because I am } \\
\text { [geographically] in the middle of them. It actually works out quite well. [...] However, for me it's a } \\
\text { tricky story, I'm not entirely happy with the situation. I think it's slightly risky. }\end{array}$ \\
\hline $\begin{array}{l}\text { Sharing of other farming } \\
\text { equipment }\end{array}$ & 6 & $\begin{array}{l}\text { We collaborate a lot in the neighbourhood. We have farmyard manure machines and arable } \\
\text { machines together, and we have certain machines together with a third or fourth farmer, but we } \\
\text { have all the harvesting machines ourselves. }\end{array}$ \\
\hline $\begin{array}{l}\text { Going to the carcass } \\
\text { collection point }\end{array}$ & 17 & $\begin{array}{l}\text { Usually, everyone is on their own. Sometimes there are queues [at the carcass collection point]. } \\
\text { Because we are not calling [to take an appointment]. We just go like that and sometimes there are } \\
\text { waiting lines, let's say. Usually, sometimes when it is a big beast we help each other [for disposal], } \\
\text { and sometimes we just stay in the car. }\end{array}$ \\
\hline
\end{tabular}

\section{External collaborators}

Collection of carcasses on the premises

Manure trade between farms

Veterinarian/official farm
visits

Feed advisor visits

\section{External visitors \\ Pets (cats, dogs)

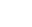

4

9

(1)

6

I do not want to have that truck [the carcass collection truck] here on the premises. I prefer to bring a dead sow there [to the carcass collection point] [...] if he would come here to me on the premises with his truck, perhaps still drenched in blood...

In terms of biosecurity, we only ensure that the farmyard manure that leaves the farm is applied by a contractor and the tools that come into contact with the manure are our own. Pumps and suction hoses, etc., are all our own material. Like this, no foreign material ever comes into contact with our manure.

[The vet] is almost never in the pigsty. Only in emergencies, otherwise he is only there to give advice and hand out medication. However, it has already happened that the vet is inside. That would basically be one of the most dangerous things. However, we have never had any negative consequences.

I know the [feed] advisor very well. Sometimes he comes by to see if there are issues. I call him, he comes, he looks and ... he comes a couple of times a year. Additionally, because we are at the same age, I see him now and then, we also went around together and therefore I know him very well.

\section{Environment/other}

Animal welfare is very important to us and that we have a farm where people can look in at any time-an open farm.

However, there can also be cats ... cats that take their kittens in the straw in the back because we have straw barns where we stock it. Because we use big quantities of straw for the pigs. Therefore, there can be cats, mice, birds...

It is fairly new [the observation of wild boars]. There were not truly wild boars in our region. They are mainly in the lake areas [...] it is rare that they come to us. However, this year I saw some with my own eyes. 


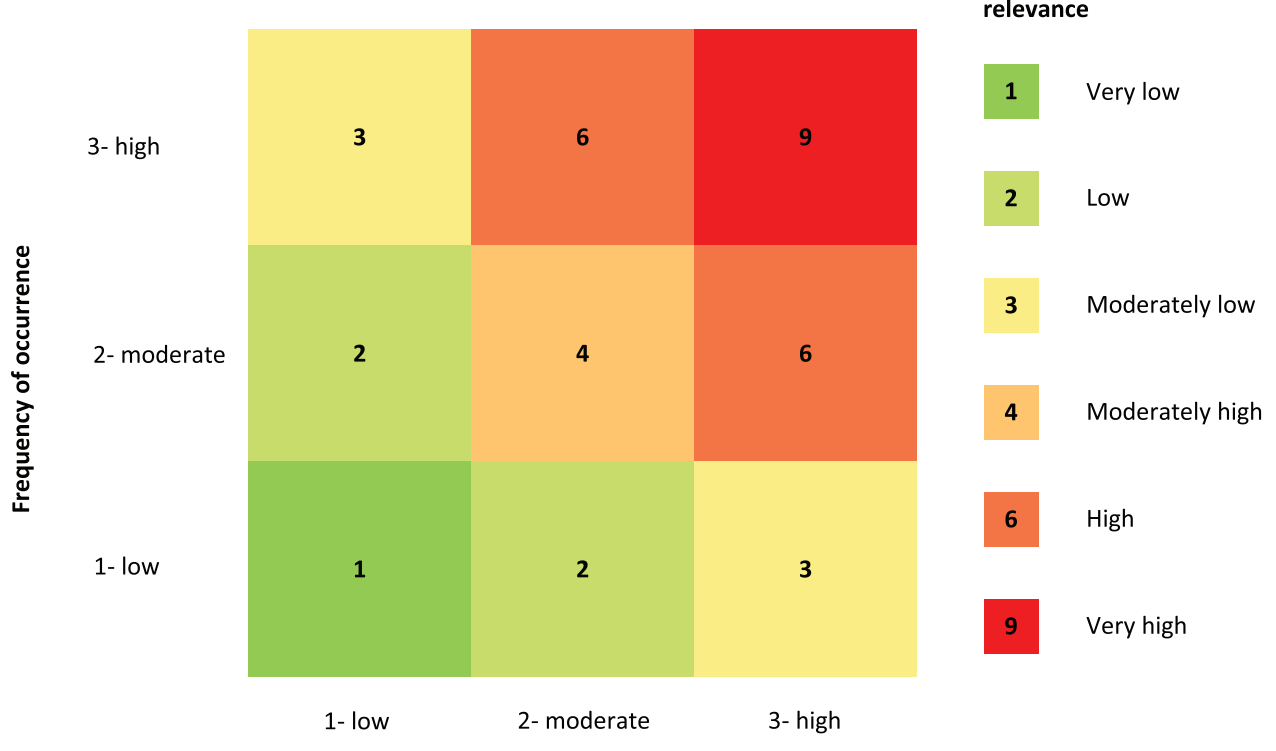

Likelihood of spread

FIGURE 1 Risk assessment matrix used to classify each potential disease pathway by relevance for disease spread, completed for each of the three diseases of interest separately. The resulting relevance scale is shown on the right side of the figure and ranges from 1, or 'very low', to 9, or 'very high'
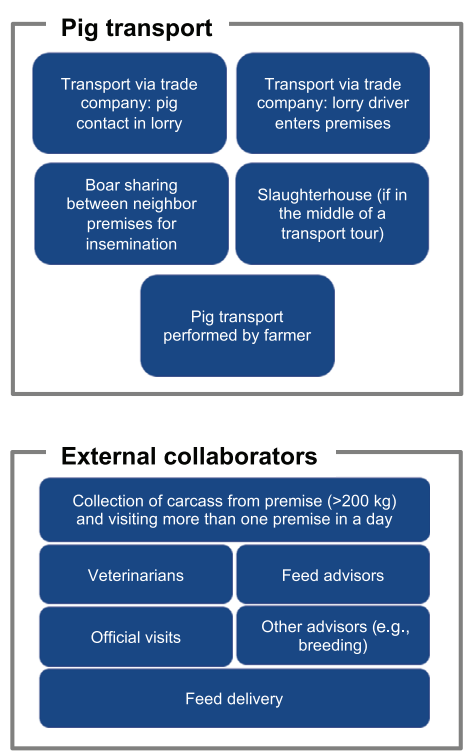
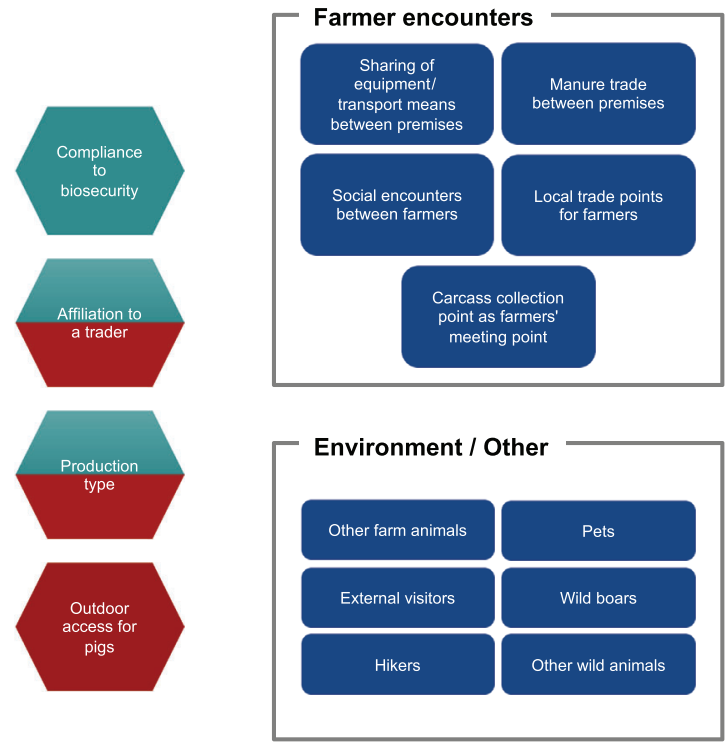

FIGURE 2 Potential disease pathways identified during the expert interviews. The bold back text on top of the four boxes indicates the general area to which the specific disease pathways (blue boxes) belong. The four hexagons in the centre display the four identified modifying factors. Green indicates a protective factor, whereas red indicates a risk factor for disease transmission. Hexagons with both colours indicate that the modifying factor may be considered protective or risk factor depending on the context

with each other in transport lorries, which sometimes cover long distances and thus provide enough time for disease propagation between batches.

Third, the possibility of outdoor access for pigs was mentioned as an additional modifying factor. Wild boar populations may contribute to farm-to-farm transmission of certain pathogens, but if pigs do not have outdoor access, they represent a less relevant threat.

Finally, experts believed that the relevance of disease pathways differs between holding production types. For instance, Switzerland has a particular farming structure termed AFP rings (AFP being the German 
acronym for 'shared piglet production'), which usually consist of one breeding station where sows are inseminated and one or several holdings where delivery, nursing, and weaning of piglets take place. Experts believed that the risk of disease spread between these farms is amplified by the numerous pig exchanges and by the sharing of equipment and frequent meetings between the owners.

Overall, all interviewed experts stressed that the many indirect contact pathways existing between Swiss pig holdings should be integrated into pig infectious disease modelling efforts to improve the realism of models for the simulation of early detection, surveillance, and control strategies.

\subsection{Farmer interviews}

The four areas of pathways identified by the experts (Figure 2) and their relation to farm characteristics were explored with the farmers and are further described in the following sections. Exemplary farmer quotes for each disease pathway are presented in Table 2.

\subsection{1 | Live pig transport}

The majority of farmers considered live pig trade as the most important mechanism of infectious disease introduction into, or spread from, their farm-except those owning closed production cycle farms, as they are rarely involved in pig trade. Recognizing the direct exposure to disease via introduction of new pigs or indirect exposure via lorry contamination during transport tours performed by traders, they adopt different strategies to minimize this risk if possible. Mitigation strategies include trading as much as possible with the same farm or requesting to the trader that their farm should be the first one visited on a transport tour.

Awareness of the risks associated with pig transport by trading companies was not uniform among the interviewees. Four distinct clusters were identified with regard to farmers' attitudes towards lorry drivers helping with the loading or unloading of pigs. Some farmers stated that drivers are aware of the most important biosecurity rules, and they never enter the stables. Other farmers expressed that lorry drivers do not access the stables but that they need to be reminded (Table 2, quote from interview 4). The remaining interviewees revealed that drivers do enter their stables, either as an exception for difficult cases or as a regular and completely acceptable practice.

Not all farmers resorted to traders for pig transport. Self-performed transports are not as much exposed to contamination issues as trader transport tours, but they present alternative potential exposure mechanisms due to the sometimes fewer professional practices compared to trader companies (Table 2, quote from interview 1). In our sample, three distinct situations were observed: farmers in the industrialized pig production areas of the country only do self-transports on rare occasions, farmers belonging to an AFP ring sometimes are not associated with a trader and perform transports personally, and farmers with small holdings outside the main pig production areas perform all transports independently.

Although most Swiss breeding holdings currently practice artificial insemination, farms with traditional reproduction or farms outside the main production area still resort to natural breeding with a boar kept on the premises. Sharing boars with neighbouring breeding farms as a courtesy between colleagues is subject to under-reporting in the official national animal transport database and is always performed by farmers themselves with the aforementioned associated risks. During the interviews, three farmers confirmed that this practice still exists today (Table 2, quote from interview 5).

\subsection{2 | Farmer encounters}

Many occasions for professional or social encounters between farmers were reported during the interviews, both on and out of the pig holdings. Farmers frequently mentioned that they are active in local, regional, or national farming associations and working groups. Regardless of the context, most interviewees strongly believed that meetings happening outside of their farming premises represent a very low risk for disease spread, as on those occasions they do not meet in work clothing (Table 2, quote from interview 1). Nevertheless, one interviewee revealed that he would meet his colleagues in work clothing.

On-farm contacts with colleagues were also mentioned. For instance, a pig fattener said he occasionally goes to his neighbour's pig stall to help him put down a sick pig (Table 2, quote from interview 12).

The sharing of pig and other farming equipment was also reported (Table 2, quotes from interviews 6 and 10). Most interviewees did not share pig farming equipment, either because they did not need to, or because they were afraid it would not be properly handled by other farmers. The most frequently shared pig farming items were aesthetic equipment (isoflurane anaesthesia) for piglet castration that is allowed to be performed by farmers after completing a training course and ultrasound machines for gestating sows. Other farming equipment, such as seeders, fertilizer spreaders, and manure tanks, was shared more often.

Visits to carcass collection points were reported by most farmers as a frequent task. Some of them said it is common to meet other farmers there or even to help other farmers in the carcass disposal process (Table 2, quote from interview 17). During the interviews, we identified three factors affecting the occurrence of this pathway: (i) accessibility: limited opening hours may result in an increased likelihood of farmer encounters while waiting for their turn to dispose of the carcass. Additional risky practices, such as asking other farmers to help in disposing of carcasses, were encouraged by limited accessibility and farmers' other engagements. (ii) Monitoring: according to the interviewees' reports, some collection points are attended by personnel, some have a camera monitoring system, and some are not monitored at all. Some farmers expressed their concerns about the lack of monitoring, as they believed it encouraged risky practices among their colleagues. (iii) Farmer's risk perception: we encountered very different 
perceptions, ranging from feeling very relaxed during the disposal process to considering visits to collection points as the most dangerous task for the health of their herd.

\subsection{3 | External collaborators}

If the carcasses to be disposed of are heavier than a certain threshold weight (usually 200 kilograms), carcass disposal companies pick them up on the premises. To avoid incurring the risk of contamination due to the collection trucks visiting several holdings on the same day, some farmers refrained from using this service and would rather manage the disposal on their own (Table 2, quote from interview 20).

According to the interviewees, pig feed advisors and veterinarians are external collaborators frequently visiting pig holdings. Both professionals are often granted access to pig stables by farmers, and both may visit multiple stables within the same day. Depending on the level of observation of biosecurity protocols by themselves and the farmers, they may act as pathogen vectors. In our sample, not all farmers were visited by feed advisors. In the case in which they were, the stated frequency of visits varied from 'once in a while' to 'every 1 or 2 months' For veterinarian visits, most farmers received visits for official controls or from farm veterinarians. The frequencies of these visits ranged between 'rarely' and 'often', the latter mostly due to piglet castration. While several farmers revealed their fear of disease introduction onto the farm via veterinarians (Table 2, quote from interview 14), only one farmer shared his worries about his feed advisor possibly bringing pathogens into the stables.

The management of manure produced on the farm is also a task requiring the support of external collaborators. Liquid manure was reported to be transported by specialized companies (Table 2, quote from interview 21). The fact that these companies handle biological material from pigs and visit several farms on the same day makes them another possible carrier of pathogenic agents. Feed delivery trucks represent a similar risk due to multiple farm visits and the potential spread of pathogens by, for example, picking up dirt from a farm with truck wheels and subsequently depositing it in other locations. Some farmers recognized this risk and adopted preventive strategies such as ordering large amounts of feed to reduce the number of feed delivery trucks or placing feed silos far from the main premises to avoid truck contamination.

\subsubsection{Environment and other contacts}

The presence of wild boars in areas with a high density of pig holdings may facilitate the farm-to-farm spread of pathogens affecting domestic pigs. Most farmers reported that wild boars were spotted in the vicinity of their holding by themselves or their neighbours. The sightings occurred in all regions where the interviews took place. Farmers with pigs having outdoor access shared their concerns about not being able to prevent contact with wild boar because, for instance, of the lack of double fencing around their farm. Some of them justified their unpre- paredness by the absence of wild boar in their region up to recent times (Table 2, quote from interview 16).

Other wild animals (e.g., rodents, birds) and pets (mainly cats) were frequently reported by farmers as being able to access the stables and potentially move from farm to farm in a short time frame. Only one farmer named such contacts in the context of potential infectious disease transmission. This interviewee believed his holding was well protected from infectious disease exposure but mentioned wild animal contact as the most likely mechanism of disease introduction.

Visits by non-professional external persons were often mentioned, for instance, in the context of the direct sale of farm products on the premises or because of the farmers' will to show their farm to people expressing an interest in it (Table 2, quote from interview 5).

\section{3 | Expert workshop}

A total of 24 potential disease pathways could be defined by combining the information collected during expert and farmer interviews and were classified during the expert workshop according to the overall frequency of occurrence and the specific likelihood of disease spread for ASF, PRRS, and EP.

The initial answers of the experts diverged most of the time (Table S3). Concerning the frequency of pathway occurrence, the same answer was given by all experts in three cases, namely for the direct trade between farms (high frequency), transport performed by the farmer (moderate frequency), and visits by feed advisors (high frequency). Unanimous initial answers about disease spread likelihood were observed slightly more often: for seven pathways in the case of ASF, for eight in the case of PRRS, and for six in the case of EP.

The final scores on frequency of occurrence and likelihood of spread on which the experts agreed after open discussion are presented in Table 3, together with the overall relevance for the three diseases of interest obtained by means of risk assessment matrices. Out of the 10 transport-related disease pathways, four seemed to have a high frequency of occurrence, which, coupled with moderate-to-high likelihood of disease transmission, resulted in high-to-very-high relevance for ASF, PRRS, and/or EP spread. Another pathway with moderateto-high relevance for disease spread was self-performed pig transport by the farmer (pathway 10). On the one hand, experts believed that farmers may wash transporters less frequently after transport or may get in contact with their colleagues more often than professional lorry drivers. On the other hand, they pointed out that farmers are considerably less likely than trader companies to visit several farms on the same day, hence having a lower relevance for disease spread compared to transports performed by traders.

Out of the five pathways in the farmer encounter area, two were classified as highly relevant for PRRS transmission. These were 'sharing of other farming equipment' (pathway 14) and 'going to the carcass collection point' (pathway 15). 'Sharing of pig farming equipment' (pathway 13) may result in a higher likelihood of pig disease transmission but happens less frequently, resulting in an overall low-to-moderately low relevance. 
TA B LE 3 Frequency of potential disease pathways between Swiss pig holdings and likelihood of spread for African swine fever (ASF), porcine reproductive and respiratory syndrome (PPRS), and enzootic pneumonia (EP) as agreed upon by participants in the final expert workshop, where 1 = low, 2 = moderate and 3 = high frequency and likelihood. The three rightmost columns show the overall relevance of pathways for the three diseases of interest ( 1 = very low to $9=$ very high, see Figure 1 ) as a product of the frequency of occurrence and likelihood of disease spread

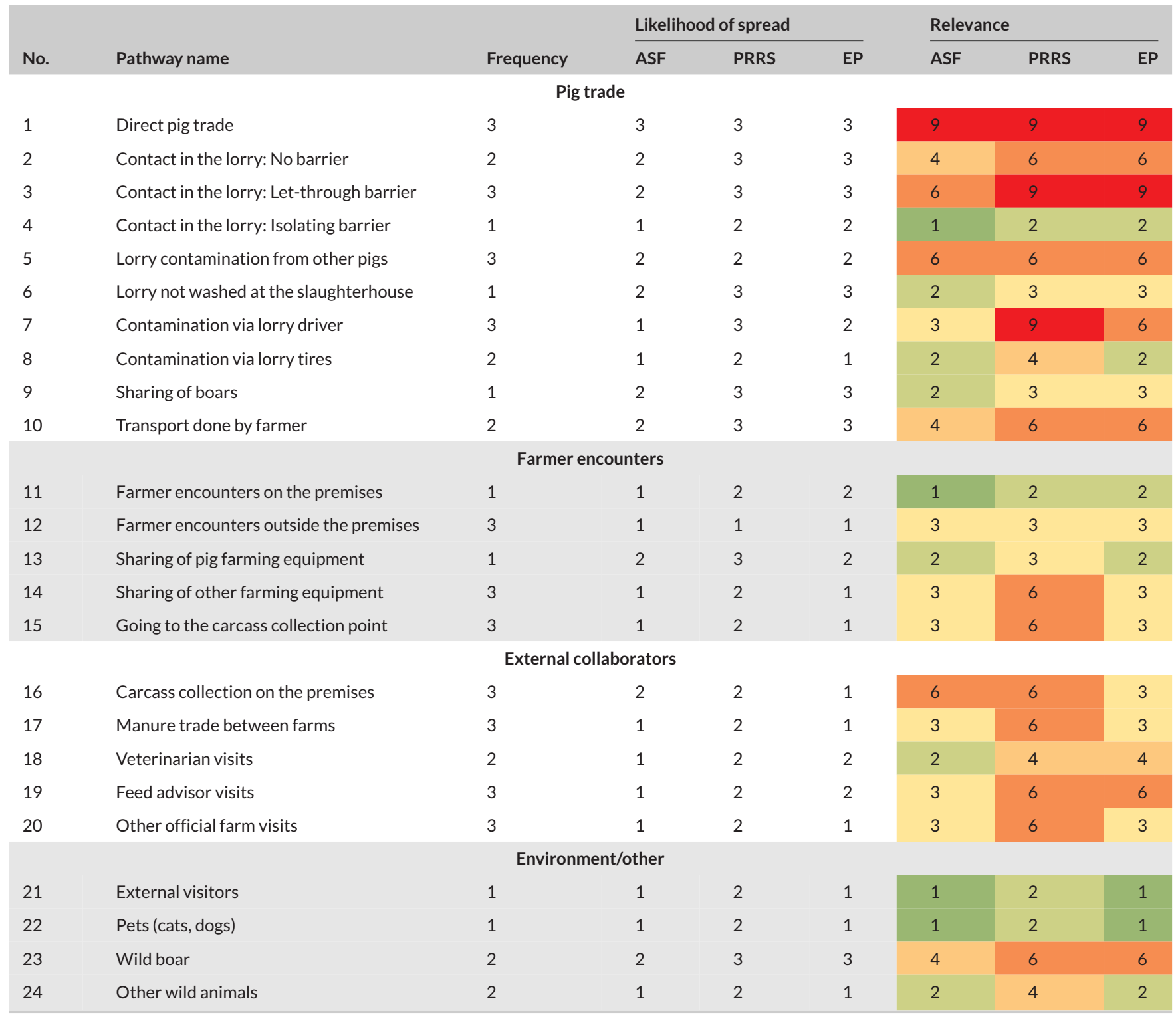

In the external collaborators area, the other carcass managementrelated practices (pathway 16) were found to be highly relevant for the spread of PRRS and ASF. Other on-farm visits from external collaborators consist of manure trade between farms, veterinarian visits, feed advisor visits, and other official farm visits. Despite the high frequency of such visits, these appear to have only low-to-moderately low relevance for propagation of ASF, as likelihood of spread was categorized as low. However, they are considered highly relevant for the transmission of PRRS, which can be propagated much more efficiently via fomites, as well as for the transmission of EPs in the case of feed advisors.

Finally, among the four environment-related contact pathways, the only one relevant for disease spread between farms is via wild boar populations that are infected from domestic pigs and spread the dis- ease further to other farms, with relevance ranging from moderately high for ASF to high for PRRS and EP. According to the discussions in the expert workshop, the reason for the relevance for ASF being lower than for the other two diseases is due to the need for close contacts for ASF transmission between domestic pigs and wild boars, whereas airborne transmission over short distances can occur for PRRS and EP.

\section{4 | DISCUSSION}

\section{1 | Likelihood of disease spread}

Our study reiterates the central role of direct pig trade in the spread of infectious diseases, which has been previously illustrated for all the 
diseases investigated here: ASF, PRRS, and EP (Gao et al., 2021; Glazunova et al., 2021; Hege et al., 2002; Kwong et al., 2013; Mortensen et al., 2002). In addition, studies of pig trade networks in different countries highlighted that accounting for trade-related indirect pathways significantly increased infectious disease spread potential (Porphyre et al., 2020; Salines et al., 2017; Sterchi et al., 2019; Thakur et al., 2015). A strength of our study is that trade-related practices are presented for the first time as 10 distinct disease pathways. This detailed categorization allows for the formulation of targeted control strategies when indirect trade-related pathways are believed to occur. Our findings indicate that in Switzerland, both traders (pathways 1, 2, 3, 5, and 7) and farmers (pathway 10) are involved in disease pathways that are highly relevant for the propagation of at least two of the three investigated diseases. In addition, farmers may have an influence on the occurrence of trader-dependent pathways through their behaviour. For instance, contamination via lorry drivers was deemed to be highly relevant for PRRS and EP, but not all farmers would let drivers be involved in the loading/unloading process. Overall, these findings highlight that while professional trade companies should perform regular biosecurity training targeting drivers, risk awareness campaigns aimed at farmers should not be neglected.

Another novelty of our study is the simultaneous examination of pathway relevance with regard to between-farm transmission for the three diseases, enabling a better targeting of those diseases and of further diseases with similar propagation mechanisms. The importance of considering pathway relevance by disease context is visible in our study, where among the 14 pathways not related to pig trade, three were at least moderately likely to result in spread of ASF, 13 in spread of PRRS, and five in spread of EP.

Sharing of pig farming equipment, carcass collection on the premises, and wild boar populations were pathways classified as moderately likely to spread ASF. The high tenacity of the ASF virus in blood and carcasses (Blome et al., 2020) leads to a high risk of transmitting the pathogen via pig farming tools, such as castration devices, and via carcass collection on the premises. However, this high tenacity of the virus that also exists in the environment was of less relevance for our study because we evaluated farm-to-farm transmission only and not the introduction of the diseases from the environment into farms. On-site pick-up of carcasses was reported in the Netherlands as a transmission route during an epidemic of the CSF virus (Elbers et al., 1999), which has shedding characteristics similar to those of the ASF virus (K. Schulz, Staubach, et al., 2017). With regard to wild boar populations, we only evaluated their relevance for farm-to-farm transmission of ASF and not the overall role of wild boar for ASF propagation within and across countries, nor the risk of incursion into a single farm depending on its biosecurity. Therefore, while both experimental and field studies attributed to wild boar a role in the transmission of ASF within the domestic pig population (Guinat et al., 2016; Nurmoja et al., 2020), we found that, compared to trade-related pathways, wild boars are less relevant for the domestic pig sector in terms of ASF transmission between farms. Nevertheless, this uncertainty regarding the relevance of wild boar for ASF spread between pig farms is reflected in the low level of agreement among experts on the relevance of the wild boar pathway for ASF transmission (Table S3). Other wild animals, as well as farm pets, were found to be of low relevance in a recent assessment of ASF transmission pathways (Mauroy et al., 2021), supporting the experts' low grading of this pathway.

For PRRS spread, almost all pathways not related to pig trade were classified at least as moderately important. This is supported by the literature, where it is reported that the virus can be shed via air over long distances (Otake et al., 2010) and is believed to have a halflife of 5 days in manure (D. C. L. Linhares et al., 2012), and infection of pigs via different fomites has been observed experimentally (Dee et al., 2002; Otake et al., 2002). Despite this evidence, local transmission was the only route, other than direct trade, considered in recent PRRS modelling (Haredasht et al., 2017; Galvis et al., 2021; VanderWaal et al., 2020). Although this local spread may be used as a proxy for indirect short-distance pathways, such as encounters between neighbouring farmers, it does not allow for the consideration of spread via long-distance mechanisms, as in the case of professional farm visits. Future PRRS modelling works must prioritize the characterization of proximity-related pathways and the inclusion of other pathways, including long-distance, indirect pathways (Arruda et al., 2018).

The pathways not linked with pig trade and classified as moderately or highly likely to spread EP were the sharing of pig farming equipment, visits by veterinarians, feed advisors and other farmers, and wild boar populations. While the overall importance of indirect pathways for the spread of EP is believed to be low (Batista et al., 2004), a recent work reported that the pathogen can survive on plastic surfaces and on dust at low temperatures for as long as 8 days (Browne et al., 2017). Our expert pool assigned a high likelihood of EP spread via wild boar, even though previous research indicates that domestic pigs likely infect wild boar, and not vice versa (M. B. Linhares et al., 2015). It is thus possible that the pathway via wild boar for EP spread is overestimated by our study, which could be caused by the overestimated impact of EP in general because, before the full implementation of a national control program in 2004, the disease was endemic in Switzerland and caused significant economic losses (Stärk et al., 2007).

\subsection{Frequency of occurrence of indirect disease pathways}

The carcass disposal process was a recurrent topic during farmers' interviews, and indirect pathways linked to it were also highlighted by the experts. Improper disposal on farm lots and movements of carcass collection trucks between farms were examined in the context of disease spread in other countries (Brennan et al., 2008; Elbers et al., 1999; Nöremark et al., 2013; Relun et al., 2015). In addition, interactions at the carcass collection points were mentioned by several farmers in our sample. To the best of our knowledge, these interactions were not previously explicitly considered as possible between-farm disease spread mechanisms. Thanks to the combined experiences of farmers and experts, we found that improving the accessibility and monitoring of carcass collection points and farmers' awareness of the risks of 
disease encounter in the disposal process may significantly decrease the relevance of this indirect pathway.

Only a few farmers reported the sharing of equipment specific to pig farming, supporting the low frequency of occurrence of this pathway assigned by the experts. However, experts mentioned that sharing of lorries for pig transport occurs frequently among farmers who are not affiliated with traders, as also reported by Relun et al. (2015), but they considered that this potentially risky practice is partially accounted for in pathway 10 ('transport done by farmer self'). In any case, sharing of equipment specifically related to pig farming may be a highly relevant disease spread pathway, as also reported in an expert elicitation study on the role of biosecurity in preventing disease incursion in Swiss pig farms, where avoiding sharing of equipment was considered an effective disease prevention strategy (Kuster et al., 2015). Sharing of farming equipment other than that specific to pig farming was classified as occurring with a high frequency in our study, which is mainly pertinent for diseases easily spreading via fomites, such as PRRS. A study assessing the sharing of equipment among cattle farms in the United Kingdom also found that a high proportion (43\%) of the farmers shared equipment, and half of them did not perform any disinfection procedure before sharing it (Brennan et al., 2008). This observed highly frequent equipment sharing in our context could thus be explained by cattle kept on pig farms, as most Swiss pig farms also keep cattle (Dürr et al., 2014).

Farmer encounters on the premises were believed to happen at a low frequency, which is in line with studies undertaken in the United States (Mcreynolds et al., 2014) and in Sweden (Nöremark et al., 2013). The latter study also reported that one third of the visiting neighbours were in direct contact with pigs or entered the stables, indicating that such encounters represent a threat for disease spread despite the low rate of occurrence.

Visits from veterinarians and feed advisors appear to be the most relevant pathways related to external collaborators. Visits of veterinarians happen frequently. Some of them are counted in our study among the official farm visit pathways, for which, according to our expert pool, biosecurity protocols are typically strictly followed. Despite the intentions of maintaining higher sanitation, veterinarian visits can potentially create long contact chains and tend to connect holdings not necessarily linked via pig trade (Rossi et al., 2017). Feed advisors also visit farms on a frequent level, and in Switzerland, they are often considered persons of trust in case of health issues in the herd, which was confirmed during our farmer interviews. Feed advisors have a similar disease spread potential as veterinarians, although they are believed to follow biosecurity routines less stringently and may therefore pose a greater threat according to our expert pool and the literature (Nöremark et al., 2010). Although veterinarians and feed advisors are not the only professional visitors of farms, other workers, such as electricians and repairmen, were not considered potential disease pathways in our study because they were mentioned in the context of disease transmission by only one expert, who believed these workers visited more than one farm per day only very rarely. Visits by these professionals were mentioned during the mental models interviews, although none of the farmers seemed to know whether the workers visited other farms before or after visiting their farms.

The experts believed that the overall frequency of external, nonprofessional visitors on pig premises relevant for disease transmission between farms is low. Although farmers selling their products on the premises may often receive visits from external visitors, these are unlikely to visit other pig farms on the same day. An intermediate frequency was assigned to wild boar as a porcine disease pathway, even though specifically considering their role for between-farm transmission only and not for disease introduction. Indeed, in Switzerland, areas densely populated with wild boar overlapped with regions with a high density of farms with outdoor access for pigs (Vargas Amado et al., n.d.), which may facilitate farm-to-farm spread of pathogens via wild boar populations.

\subsection{Factors modifying the relevance of disease pathways}

The aforementioned role of outdoor access for pigs as a modifying factor for the exposure to wild boar is one example of how farm characteristics should be considered when interpreting our findings. Production type is another important factor. Upstream farms in the production chain, such as breeding farms, are traditionally considered a bigger threat for disease spread via pig trade. Among our sample of farmers, we observed that fattening and closed-cycle production farms could also potentially infect other farms via indirect disease pathways (Table 2, quotes from interviews 1, 4, 5, 6, 13, 17, and 19). When modelling the transmission of PRRSV, Galvis et al. (2021) indeed found that fattening farms were involved in local disease spread. Another example of production type influencing contact pathways is that of carcass collection on the farm. This pathway was found by the experts to be frequent, but since carcass collection centres mainly offer this service for carcasses weighing 200 kilograms or more, it may more often occur on farms owning old breeding animals.

Following biosecurity protocols effectively mitigates the risk of disease transmission, especially for indirect pathways that cannot be eliminated even during outbreaks, such as veterinarian visits (Mcreynolds et al., 2014). In Switzerland, some biosecurity measures concerning animal transport are defined by law, as well as the obligation to dispose of carcasses at the defined collection points (Swiss Federal Food Safety and Veterinary Office, 2011). Most biosecurity protocols are nonetheless formulated as recommendations, and their application is left to the individual responsibility of farmers. These recommendations include avoiding the sharing of farm equipment, providing external visitors with farm-specific protective clothing and footwear, and changing clothing and thoroughly washing hands after carcass disposal ('Gesunde Nutztiere-Guide de La Biosécurité', n.d.). Especially for biosecurity protocols presented as recommendations, trust might be an important aspect when considering their application. A higher trust in colleagues or external collaborators might be associated with lower biosecurity (e.g., if biosecurity measures are not observed by the 
trusted party). In contrast, the trust or distrust placed in colleagues and external collaborators might serve as a protective factor for disease spread. Among the interviewed farmers, this could be observed in several situations involving both colleagues (e.g., trusting colleagues to dispose of pig carcasses from their farm, or not trusting them to use their equipment) and external collaborators (e.g., trusting feed advisors to enter the stables, or not trusting carcass collection services to come on the premises). In future research, it might be advantageous to consider psychological factors, such as trust, as vulnerability or protective factors.

\subsection{The mental models approach}

The use of an adapted MMA in this context was found to present multiple advantages. First, the MMA provided the flexibility to be able to include further pathways in every step of data collection. Thanks to that, we gained knowledge on pathways that had not been considered in past works. Second, accessing the combined knowledge of farmers and experts proved to be a powerful tool for evaluating the importance of indirect disease pathways, as both deal with issues related to pig production and health but from different perspectives. Third, interviewing farmers by means of semi-structured interviews allowed us to simultaneously identify pathways and learn about farmers' attitudes and perceptions towards them. Open face-to-face interviews were very effective in this process, as they greatly facilitated the building of trust towards interviewers and the sharing of information on sometimes frowned upon farming practices (Relun et al., 2015). Finally, expert elicitation enabled the generalization of findings from the limited sample of interviewed farmers to the country context and to assess their relevance for the spread of three diseases of national and international concern.

\subsection{Study limitations}

The limitations of our study are mainly those associated with qualitative assessments of the pathways that are typically undertaken relying on limited samples. The number of elicited experts is small but justifiable given the size of the country and the limited number of available experts in the field, as previously reported by another expert elicitation study in Switzerland (Kuster et al., 2015). We coped with this limitation by selecting an expert sample as diversified as possible, and we provided the counts of single expert answers given during the workshop, which can be used to interpret with caution the relevance of pathways with low agreement among experts. The small sample of farmers did not allow for the investigation of the association between the responses provided by farmers and farm characteristics. A further quantitative study may be considered to draw further conclusions in these regards. Nonetheless, some of the associations are relatively straightforward, as in the case of the wild boar pathway and outdoor access for pigs, and can be extrapolated by using national agricultural and other databases. Finally, the presented frequencies of disease pathway occurrence are based on expert opinions given in the absence of outbreaks in the country. This may significantly vary through behaviour change of farmers and professionals in reaction to disease incursion, which may in turn change the frequencies of disease pathway occurrence. This shift in behaviour must be considered when modelling disease spread after detection.

\section{CONCLUSION}

In this study, we identified 24 pathways for the farm-to-farm transmission of porcine infectious diseases, including the direct way through animal transport and indirect modes by people, vehicles, and other fomites. The high relevance of many of these pathways highlights that neglecting them during outbreak investigations or disease modelling research may have substantial repercussions, especially following the introduction of pathogens that are easily transmitted via fomites and aerosols. Our disease-specific risk classification of these pathways makes a valuable contribution to comprehensive surveillance and control strategies. While the simple scaling system we adopted does not result in exact parameter estimates applicable to disease transmission simulation models, it allows estimating parameters for given pathways relative to those already known in the literature. In addition, the parallel exploration of farmers' practices, attitudes, and perceptions towards potential disease pathways performed in our study makes it possible to relate the findings to the target community for disease surveillance and control.

\section{ACKNOWLEDGEMENTS}

The authors would like to thank the Swiss National Science Foundation (SNSF; project number 182404) for providing funding for this study. We acknowledge Dominik Hummel for performing some of farmer interviews. We would like to thank both farmers and experts who kindly agreed to participate in the study and let us access their knowledge and experience. Finally, we thank SUISAG AG for the support provided in the farmer recruitment process.

Open access funding provided by Universitat Bern.

\section{CONFLICT OF INTEREST}

The authors declare no conflict of interest.

\section{ETHICS STATEMENT}

The authors confirm that the ethical policies of the journal, as noted on the journal's author guidelines page, have been adhered to and the ethical review committee approval has been received from the Ethics Committee of the Swiss Federal Institute of Technology Zurich (ETHZ) prior to interviews with Swiss pig farmers (EK 2019-N-167).

\section{DATA AVAILABILITY STATEMENT}

Some of the data that support the findings of this study are available in the Supporting Information of this article. The remaining data (farmer 
interview records and transcripts) are not publicly available due to privacy or ethical restrictions.

\section{ORCID}

Francesco Galli (D) https://orcid.org/0000-0002-3855-4514

\section{REFERENCES}

Amirpour Haredasht, S., Polson, D., Main, R., Lee, K., Holtkamp, D., \& Martínez-López, B. (2017). Modeling the spatio-temporal dynamics of porcine reproductive $\&$ respiratory syndrome cases at farm level using geographical distance and pig trade network matrices. BMC Veterinary Research, 13(1), 163. https://doi.org/10.1186/S12917-017-1076-6

Arruda, A. G., Sanhueza, J., Corzo, C., \& Vilalta, C. (2018). Assessment of area spread of porcine reproductive and respiratory syndrome (PRRS) virus in three clusters of swine farms. Transboundary and Emerging Diseases, 65(5), 1282-1289. https://doi.org/10.1111/TBED.12875

Bajardi, P., Barrat, A., Savini, L., \& Colizza, V. (2012). Optimizing surveillance for livestock disease spreading through animal movements. Journal of the Royal Society, Interface, 9(76), 2814-2825. https://doi.org/10.1098/rsif. 2012.0289

Bard, A. M., Main, D., Roe, E., Haase, A., Whay, H. R., \& Reyher, K. K. (2019). To change or not to change? Veterinarian and farmer perceptions of relational factors influencing the enactment of veterinary advice on dairy farms in the United Kingdom. Journal of Dairy Science, 102(11), 10379-10394. https://doi.org/10.3168/JDS.2019-16364

Batista, L., Pijoan, C., Ruiz, A., Utrera, V., \& Dee, S. (2004). Assessment of transmission of Mycoplasma hyopneumoniae by personnel. Journal of Swine Health and Production, 12(2), 75-77. http://www.aasv.org/shap. html

Bearth, A., Cousin, M. E., \& Siegrist, M. (2014). Poultry consumers' behaviour, risk perception and knowledge related to campylobacteriosis and domestic food safety. Food Control, 44, 166-176. https://doi.org/10. 1016/j.foodcont.2014.03.055

Blome, S., Franzke, K., \& Beer, M. (2020). African swine fever-A review of current knowledge. Virus Research, 287, 198099. https://doi.org/10. 1016/J.VIRUSRES.2020.198099

Brennan, M. L., Kemp, R., \& Christley, R. M. (2008). Direct and indirect contacts between cattle farms in north-west England. Preventive Veterinary Medicine, 84(3-4), 242-260. https://doi.org/10.1016/J.PREVETMED. 2007.12.009

Browne, C., Loeffler, A., Holt, H. R., Chang, Y. M., Lloyd, D. H., \& Nevel, A. (2017). Low temperature and dust favour in vitro survival of Mycoplasma hyopneumoniae: Time to revisit indirect transmission in pig housing. Letters in Applied Microbiology, 64(1), 2-7. https://doi.org/10.1111/LAM. 12689

Corbin, J., \& Strauss, A. (2012). Basics of qualitative research (3rd ed.): Techniques and procedures for developing grounded theory. SAGE Publications, Inc. https://doi.org/10.4135/9781452230153

Dee, S., Deen, J., Rossow, K., Wiese, C., Otake, S., Joo, H. S., \& Pijoan, C. (2002). Mechanical transmission of porcine reproductive and respiratory syndrome virus throughout a coordinated sequence of events during cold weather. Canadian Journal of Veterinary Research = Revue Canadienne de Recherche Veterinaire, 66(4), 232-239. https://pubmed.ncbi.nIm. nih.gov/12418778/

Dürr, S., Fasel-Clemenz, C., Thür, B., Schwermer, H., Doherr, M. G., Dohna, H. Z., Carpenter, T. E., Perler, L., \& Hadorn, D. C. (2014). Evaluation of the benefit of emergency vaccination in a foot-and-mouth disease free country with low livestock density. Preventive Veterinary Medicine, 113(1), 34-46. https://doi.org/10.1016/J.PREVETMED.2013.10.015

Elbers, A. R. W., Stegeman, A., Moser, H., Ekker, H. M., Smak, J. A., \& Pluimers, F. H. (1999). The classical swine fever epidemic 1997-1998 in the Netherlands: Descriptive epidemiology. Preventive Veterinary Medicine, 42(3-4), 157-184. https://doi.org/10.1016/S0167-5877(99)00074-4
Galvis, J. A., Corzo, C. A., Prada, J. M., \& Machado, G. (2021). Modelling the transmission and vaccination strategy for porcine reproductive and respiratory syndrome virus. Transboundary and Emerging Diseases, 69, 485-500. https://doi.org/10.1111/TBED.14007

Gao, X., Liu, T., Liu, Y., Xiao, J., \& Wang, H. (2021). Transmission of African swine fever in China through legal trade of live pigs. Transboundary and Emerging Diseases, 68(2), 355-360. https://doi.org/10.1111/TBED. 13681

Gesunde Nutztiere-Guide de la biosécurité. (n.d.). https://www.animauxde-rente-sains.ch/fr/guide-de-la-biosecurite/?oid=90\&lang=fr

Glazunova, A. A., Korennoy, F. I., Sevskikh, T. A., Lunina, D. A., Zakharova, O. I., Blokhin, A. A., Karaulov, A. K., \& Gogin, A. E. (2021). Risk factors of African swine fever in domestic pigs of the Samara Region, Russian Federation. Frontiers in Veterinary Science, 8, 723375. https://doi.org/10. 3389/FVETS.2021.723375

Guinat, C., Gogin, A., Blome, S., Keil, G., Pollin, R., Pfeiffer, D. U., \& Dixon, L. (2016). Review: Transmission routes of African swine fever virus to domestic pigs: Current knowledge and future research directions. The Veterinary Record, 178(11), 262. https://doi.org/10.1136/VR.103593

Halasa, T., Bøtner, A., Mortensen, S., Christensen, H., Toft, N., \& Boklund, A. (2016). Simulating the epidemiological and economic effects of an African swine fever epidemic in industrialized swine populations. Veterinary Microbiology, 193, 7-16. https://doi.org/10.1016/J.VETMIC.2016. 08.004

Hege, R., Zimmermann, W., Scheidegger, R., \& Stärk, K. D. C. (2002). Incidence of reinfections with Mycoplasma hyopneumoniae and Actinobacillus pleuropneumoniae in pig farms located in respiratory-disease-free regions of Switzerland-Identification and quantification of risk factors. Acta Veterinaria Scandinavica, 43(3), 145-156.

Jones, N. A., Ross, H., Lynam, T., Perez, P., \& Leitch, A. (2011). Mental models: An interdisciplinary synthesis of theory and methods. Ecology and Society, 16(1), 46. https://www.ecologyandsociety.org/vol16/iss1/art46/

Kuster, K., Cousin, M. E., Jemmi, T., Schüpbach-Regula, G., \& Magouras, I. (2015). Expert opinion on the perceived effectiveness and importance of on-farm biosecurity measures for cattle and swine farms in Switzerland. PLoS One, 10(12), e0144533. https://doi.org/10.1371/journal.pone. 0144533

Kwong, G. P. S., Poljak, Z., Deardon, R., \& Dewey, C. E. (2013). Bayesian analysis of risk factors for infection with a genotype of porcine reproductive and respiratory syndrome virus in Ontario swine herds using monitoring data. Preventive Veterinary Medicine, 110(3-4), 405-417. https://doi.org/ 10.1016/J.PREVETMED.2013.01.004

Lentz, H. H. K., Koher, A., Hövel, P., Gethmann, J., Sauter-Louis, C., Selhorst, T., \& Conraths, F. J. (2016). Disease spread through animal movements: A static and temporal network analysis of pig trade in Germany. PLoS One, 11(5), e0155196. https://doi.org/10.1371/journal.pone.0155196

Linhares, D. C. L., Torremorell, M., Joo, H. S., \& Morrison, R. B. (2012). Infectivity of PRRS virus in pig manure at different temperatures. Veterinary Microbiology, 160(1-2), 23-28. https://doi.org/10.1016/J.VETMIC. 2012.05.009

Linhares, M. B., Belloy, L., Origgi, F. C., Lechner, I., Segner, H., \& RyserDegiorgis, M. P. (2015). Investigating the role of free-ranging wild boar (Sus scrofa) in the re-emergence of enzootic pneumonia in domestic pig herds: A pathological, prevalence and risk-factor study. PLoS One, 10(3), e0119060. https://doi.org/10.1371/JOURNAL.PONE. 0119060

Manuele, F. A. (2013). Acceptable risk. In F. A. Manuele (Ed.), On the practice of safety (pp. 102-124). John Wiley \& Sons, Ltd. https://doi.org/10.1002/ 9781118574683.CH6

Mauroy, A., Depoorter, P., Saegerman, C., Cay, B., De Regge, N., Filippitzi, M. E., Fischer, C., Laitat, M., Maes, D., Morelle, K., Nauwynck, H., Simons, X., van den Berg, T., Huffel, X. V., Thiry, E., \& Dewulf, J. (2021). Semi-quantitative risk assessment by expert elicitation of potential introduction routes of African swine fever from wild reservoir to domestic pig industry and subsequent spread during the Belgian outbreak 
(2018-2019). Transboundary and Emerging Diseases, 68, 2761-2773. https://doi.org/10.1111/tbed.14067

Mcreynolds, S. W., Sanderson, M. W., Reeves, A., Sinclair, M., Hill, A. E., \& Salman, M. D. (2014). Direct and indirect contact rates among livestock operations in Colorado and Kansas. Journal of the American Veterinary Medical Association, 244(9), 1066-1074. https://doi.org/10.2460/ JAVMA.244.9.1066

Morgan, M. G., Fischhoff, B., Bostrom, A., \& Atman, C. J. (2002). Risk communication: A mental models approach. Cambridge University Press.

Mortensen, S., Stryhn, H., Sogaard, R., Boklund, A., Stärk, K. D. C., Christensen, J., \& Willeberg, P. (2002). Risk factors for infection of sow herds with porcine reproductive and respiratory syndrome (PRRS) virus. Preventive Veterinary Medicine, 53(1-2), 83-101. https://doi.org/ 10.1016/S0167-5877(01)00260-4

Nathues, C., Perler, L., Bruhn, S., Suter, D., Eichhorn, L., Hofmann, M., Nathues, H., Baechlein, C., Ritzmann, M., Palzer, A., Grossmann, K., Schüpbach-Regula, G., \& Thür, B. (2016). An outbreak of porcine reproductive and respiratory syndrome virus in Switzerland following import of boar semen. Transboundary and Emerging Diseases, 63(2), e251-e256. https://doi.org/10.1111/tbed.12262

Nöremark, M., Frössling, J., \& Lewerin, S. S. (2013). A survey of visitors on Swedish livestock farms with reference to the spread of animal diseases. BMC Veterinary Research, 9, 184. https://doi.org/10.1186/1746-6148-9184

Nöremark, M., Frössling, J., \& Lewerin, S. S. (2010). Application of routines that contribute to on-farm biosecurity as reported by Swedish livestock farmers. Transboundary and Emerging Diseases, 57(4), 225-236. https:// doi.org/10.1111/J.1865-1682.2010.01140.X

Nurmoja, I., Mõtus, K., Kristian, M., Niine, T., Schulz, K., Depner, K., \& Viltrop, A. (2020). Epidemiological analysis of the 2015-2017 African swine fever outbreaks in Estonia. Preventive Veterinary Medicine, 181, 104556. https://doi.org/10.1016/J.PREVETMED.2018.10.001

Olofsson, E., Nöremark, M., \& Lewerin, S. S. (2014). Patterns of betweenfarm contacts via professionals in Sweden. Acta Veterinaria Scandinavica, 56(1), 70. https://doi.org/10.1186/S13028-014-0070-2

Otake, S., Dee, S. A., Acvm, D., Rossow, K. D., Deen, J., Abvp, D., Joo, H., Molitor, T. W., \& Pijoan, C. (2002). Transmission of porcine reproductive and respiratory syndrome virus by fomites (boots and coveralls). Journal of Swine Health and Production, 10(2), 59-65. http://www.aasv.org/shap. html

Otake, S., Dee, S., Corzo, C., Oliveira, S., \& Deen, J. (2010). Long-distance airborne transport of infectious PRRSV and Mycoplasma hyopneumoniae from a swine population infected with multiple viral variants. Veterinary Microbiology, 145(3-4), 198-208. https://doi.org/10.1016/J. VETMIC.2010.03.028

Porphyre, T., de C Bronsvoort, B. M., Gunn, G. J., \& Correia-Gomes, C. (2020). Multilayer network analysis unravels haulage vehicles as a hidden threat to the British swine industry. Transboundary and Emerging Diseases, 67(3), 1231-1246. https://doi.org/10.1111/TBED.13459

Relun, A., Charrier, F., Trabucco, B., Maestrini, O., Molia, S., Chavernac, D., Grosbois, V., Casabianca, F., Etter, E., \& Jori, F. (2015). Multivariate analysis of traditional pig management practices and their potential impact on the spread of infectious diseases in Corsica. Preventive Veterinary Medicine, 121(3-4), 246-256. https://doi.org/10.1016/j.prevetmed. 2015.07.004

République et canton de Neuchâtel. (n.d.). Maladie contagieuse chez les porcs. https://www.ne.ch/medias/Pages/20200508_Maladieporcs.aspx

Ribbens, S., Dewulf, J., Koenen, F., Mintiens, K., de Kruif, A., \& Maes, D. (2009). Type and frequency of contacts between Belgian pig herds. Preventive Veterinary Medicine, 88(1), 57-66. https://doi.org/10.1016/J. PREVETMED.2008.08.002

Rossi, G., de Leo, G. A., Pongolini, S., Natalini, S., Zarenghi, L., Ricchi, M., \& Bolzoni, L. (2017). The potential role of direct and indirect contacts on infection spread in dairy farm networks. PLoS Computational Biology, 13(1), e1005301. https://doi.org/10.1371/journal.pcbi.1005301
Salines, M., Andraud, M., \& Rose, N. (2017). Pig movements in France: Designing network models fitting the transmission route of pathogens. PLoS One, 12(10), e0185858. https://doi.org/10.1371/JOURNAL.PONE. 0185858

Sauter-Louis, C., Forth, J. H., Probst, C., Staubach, C., Hlinak, A., Rudovsky, A., Holland, D., Schlieben, P., Göldner, M., Schatz, J., Bock, S., Fischer, M., Schulz, K., Homeier-Bachmann, T., Plagemann, R., Klaaß, U., Marquart, R., Mettenleiter, T. C., Beer, M., \& Blome, S. (2021). Joining the club: First detection of African swine fever in wild boar in Germany. Transboundary and Emerging Diseases, 68(4), 1744-1752. https://doi.org/10.1111/ TBED.13890

Schulz, J., Boklund, A., Halasa, T. H. B., Toft, N., \& Lentz, H. H. K. (2017). Network analysis of pig movements: Loyalty patterns and contact chains of different holding types in Denmark. PLoS One, 12(6), e0179915. https:// doi.org/10.1371/JOURNAL.PONE.0179915

Schulz, K., Staubach, C., \& Blome, S. (2017). African and classical swine fever: Similarities, differences and epidemiological consequences. Veterinary Research, 48(1), 1-13. https://doi.org/10.1186/S13567-017-0490X/TABLES/1

STAR-IDAZ IRC. (2021). Annual state-of-the-art report on animal health research on IRC priorities. https://www.star-idaz.net/app/uploads/ 2019/11/State-of-the-art-report_Oct-2019_HR.pdf

Stärk, K. D. C., Miserez, R., Siegmann, S., Ochs, H., \& Schmidt, J. (2007). A successful national control programme for enzootic respiratory diseases in pigs in Switzerland. Revue scientifique et technique (International Office of Epizootics), 26(3), 595-606.

Sterchi, M., Faverjon, C., Sarasua, C., Vargas, M. E., Berezowski, J., Bernstein, A., Grütter, R., \& Nathues, H. (2019). The pig transport network in Switzerland: Structure, patterns, and implications for the transmission of infectious diseases between animal holdings. PLoS One, 14(5), e0217974. https://doi.org/10.1371/journal.pone.0217974

Suit-B, Y., Hassan, L., Krauss, S. E., Ramanoon, S. Z., Ooi, P. T., Yasmin, A. R., \& Epstein, J. (2020). Exploring the mental model of cattle farmers in disease prevention and control practices. Veterinary Sciences, 7(1), 27. https://doi. org/10.3390/VETSCI7010027

Swiss Federal Food Safety and Veterinary Office. (2011). Ordonnance concernant les sous-produits animaux.

Swiss Federal Food Safety and Veterinary Office. (2021). Überwachungsund Früherkennungsprogramme 2020: Der Gesundheitszustand der Nutztiere in der Schweiz ist gut. https://www.blv.admin.ch/blv/de/home/ tiere/tiergesundheit/ueberwachung.html

Thakur, K. K., Revie, C. W., Hurnik, D., Poljak, Z., \& Sanchez, J. (2015). Simulation of between-farm transmission of porcine reproductive and respiratory syndrome virus in Ontario, Canada using the North American Animal Disease Spread Model. Preventive Veterinary Medicine, 118(4), 413-426. https://doi.org/10.1016/j.prevetmed.2015.01.006

Tong, A., Sainsbury, P., \& Craig, J. (2007). Consolidated criteria for reporting qualitative research (COREQ): A 32-item checklist for interviews and focus groups. International Journal for Quality in Health Care: Journal of the International Society for Quality in Health Care, 19(6), 349-357. https://doi.org/10.1093/INTQHC/MZM042

VanderWaal, K., Paploski, I. A. D., Makau, D. N., \& Corzo, C. A. (2020). Contrasting animal movement and spatial connectivity networks in shaping transmission pathways of a genetically diverse virus. Preventive Veterinary Medicine, 178, 104977. https://doi.org/10.1016/j.prevetmed.2020. 104977

Vargas Amado, M. E., Carmo, L. P., Berezowski, J., Fischer, C., João Santos, M., \& Grütter, R. (n.d.). Towards risk-based surveillance of African swine fever in Switzerland. https://doi.org/10.1101/2021.05.17.444420

VERBI Software. (2019). MAXQDA 2020 [computer software]. Berlin, Germany: VERBI Software. Available from maxqda.com

Vergne, T., Guinat, C., Petkova, P., Gogin, A., Kolbasov, D., Blome, S., Molia, S., Ferreira, J. P., Wieland, B., Nathues, H., \& Pfeiffer, D. U. (2016). Attitudes and beliefs of pig farmers and wild boar hunters towards reporting of African swine fever in Bulgaria, Germany and the 
western part of the Russian Federation. Transboundary and Emerging Diseases, 63(2), e194-e204. https://doi.org/10.1111/TBED.12254

\section{SUPPORTING INFORMATION}

Additional supporting information can be found online in the Supporting Information section at the end of this article.
How to cite this article: Galli, F., Friker, B., Bearth, A., \& Dürr, S. (2022). Direct and indirect pathways for the spread of African swine fever and other porcine infectious diseases: An application of the mental models approach. Transboundary and Emerging Diseases, 1-15. https://doi.org/10.1111/tbed.14605 